\title{
Fundos de pensão no Brasil: princípios para uma crítica marxista
}

\author{
Thaís Soares Caramuru ${ }^{1}$ \\ http://orcid.org/0000-0002-6828-1377 \\ ${ }^{1}$ Universidade de Brasília, Departamento de Serviço Social, Programa de Pós-Graduação em Política Social, Brasília, DF, Brasil.
}

\section{Fundos de pensão no Brasil: princípios para uma crítica marxista}

Resumo: Sob a égide do acabouço teórico-metodológico marxista, este artigo tem por objetivo propor elementos críticos à dinâmica de funcionamento dos fundos de pensão no Brasil. Articulando-se a revisão bibliográfica sobre a temática e o uso de dados empíricos, o texto divide-se em duas seções. A primeira oferece uma visão panorâmica acerca do papel de tais fundos em países centrais e periféricos, tendo em perspectiva seu lugar estrutural no contexto capitalista de mundialização, crise estrutural e ofensiva neoliberal. A segunda seção apresenta as etapas estruturantes que forneceram as bases materiais para expansão dos ativos dos fundos de pensão no país, com destaque para os fundos destinados a servidores públicos. O artigo revela o maciço poder monetário desses fundos e sugere validade à hipótese de que estão configurados para estarem a serviço da alimentação dos mercados financeiros, em detrimento da proteção previdenciária.

Palavras-chave: Crítica marxista. Fundos de pensão. Privatização.

\section{Pension Funds in Brazil: Principles for a Marxist Criticism}

Abstract: This article uses the Marxist theoretical-methodological framework to propose critical elements to the dynamics of the operation of pension funds in Brazil. This study consisted of a literature review and the use of empirical data. The text is divided into two sections, the first provides an overview of the role of such funds in central and peripheral countries, with a view to their structural place in the capitalist context of globalization, structural crisis, and neoliberal offensive. The second section presents the structuring steps that provided the material basis for the expansion of pension fund assets in the country, with emphasis on funds intended for civil servants. The article reveals the massive financial power of these funds and suggests the validity of the hypothesis that they are designed to serve the financial markets, to the detriment of social security protection.

Keywords: Marxist criticism. Pension funds. Privatization.

Recebido em 18.12.2019. Aprovado em 16.04.2019. Revisado em 09.08.2019.

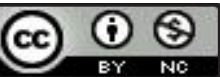

(C) O(s) Autor(es). 2019 Acesso Aberto Esta obra está licenciada sob os termos da Licença Creative Commons Atribuição-NãoComercial 4.0 Internacional (https://creativecommons.org/licenses/by-nc/4.0/deed.pt_BR), que permite copiar, distribuir e reproduzir em qualquer meio, bem como adaptar, transformar e criar a partir deste material, desde que para fins não comerciais e que você forneça o devido crédito aos autores e a fonte, insira um link para a Licença Creative Commons e indique se mudanças foram feitas. 


\section{Introdução}

Os fundos de pensão são objetos de estudos em diversas disciplinas, como economia, contabilidade, administração e direito. A depender da área do saber, pesquisas aplicam distintos enfoques à abordagem do tema. Por exemplo, Pinheiro (2007) tem como objeto a análise das implicações das mudanças demográficas nos fundos de pensão, por seu turno, Henrique (2018) adota uma abordagem jurídica, com a finalidade de examinar o marco normativo-legal do setor no Brasil. Em geral, tais investigações incorporam o pressuposto de que os fundos de pensão se constituem em instrumentos que fornecem proteção previdenciária.

A análise deste artigo contrapõe-se a tal postulado e adota a hipótese de que os fundos de pensão não estão configurados para prover proteção social, mas para fornecer amplas massas monetárias à acumulação capitalista. Sustentado por tal hipótese, este texto tem o objetivo de propor elementos para uma crítica à dinâmica de funcionamento dos fundos de pensão no Brasil.

A perspectiva teórico-metodológica adotada é a marxista, a qual mostra-se mais apropriada, pelos seguintes motivos: concebe a sociedade burguesa como uma organização social em constante e dinâmico movimento; interpreta a realidade na perspectiva da totalidade do ser social, levando em consideração que a (re)produção das relações sociais no modo de produção capitalista pressupõem a exploração da classe desprovida dos meios de produção pela classe proprietária; em tempos de agudização da crise capitalista, compreende os fundos de pensão como mecanismos postos em marcha com fins de recompor as taxas de lucro. (GRANEMANN, 2012; MONTORO, 2016).

Quanto aos instrumentos metodológicos, articula-se a revisão bibliográfica com a ponderação crítica de dados fornecidos por instituições que produzem dados empíricos sobre fundos de pensão, como a Associação Brasileira das Entidades Fechadas de Previdência Complementar (ABRAPP) e, na cena internacional, a Organização para a Cooperação e o Desenvolvimento Econômico (OCDE) e o Thinking Ahead Institue - Willis Towers Watson.

A crítica marxista ao objeto em tela reveste-se de relevância política e social, pois os regimes públicos de previdência social, instituídos pela Constituição Federal (CF) de 1988 (BRASIL, [2019a]), se encontram no epicentro da agudização da ofensiva burguesa à classe trabalhadora brasileira. Assim, acredita-se que uma das formas de defender o direito ao acesso à proteção previdenciária implica a denúncia do caráter não previdenciário dos produtos financeiros ofertados pela previdência privada, o que se pretende aqui esboçar, no âmbito dos fundos de pensão.

Para além desta introdução e das considerações finais, este artigo está estruturado em duas seções: a primeira dimensiona os fundos de pensão no capitalismo contemporâneo, a partir de uma visão panorâmica de seu papel em países centrais e periféricos; a segunda delinea as etapas estruturantes que forneceram as bases materiais da expansão desses fundos no Brasil.

\section{Fundos de pensão nos países capitalistas centrais e periféricos}

No Brasil e no resto do mundo, os fundos de pensão constituem um segmento da assim chamada, previdência privada, e recebem a denominação de entidades fechadas de previdência complementar ${ }^{1}$ (EFPC), as quais são sem finalidade lucrativa e podem ser criadas por empresas, grupos de empresas, associações profissionais e classistas. A filiação a tais instituições depende de vínculo empregatício e/ou inserção em categoria laboral, de modo que os fundos agregam, em termos de filiação, grupos específicos de trabalhadores/ as. A Organization for Economic Co-operation and Development (OECD) (2018a) aponta que os fundos de pensão ocupacionais ${ }^{2}$ (occupational pension funds) são os que oferecem maior potencial de acúmulo monetário, pois as filiações dependem de uma relação de emprego.

No capitalismo contemporâneo - configurado pela mundialização financeira, pela agudização da crise do capital, bem como pela ofensiva burguesa neoliberal -, os fundos de pensão exercem um notável papel para a acumulação. Segundo Chesnais (2005), no cenário da mundialização e reconstituição do espaço financeiro mundial, proliferam-se a liberalização dos mercados financeiros, a desregulamentação, as desintermediações e as privatizações, conformando uma conjuntura na qual os investidores institucionais ${ }^{3}$, como os fundos de pensão, "[...] fizeram da centralização dos lucros não reinvestidos das empresas e das rendas não consumidas das famílias, especialmente os planos de previdência privados e a poupança salarial, o trampolim para uma acumulação financeira de grande dimensão". (CHESNAIS, 2005, p. 36).

No contexto do aprofundamento da crise capitalista, a privatização de empresas, serviços, equipamentos e dos regimes previdenciários públicos constituem um processo cuja função primordial é "abrir espaços de rentabilidade para a acumulação" (MONTORO, 2016, p. 388, tradução nossa). Ademais, no cenário da ofen- 
siva burguesa neoliberal, cujo um dos pressupostos é o desmantelamento dos sistemas públicos de previdência, a proliferação dos fundos de pensão ganha peculiar impulso, haja vista que, "Nos países onde a previdência privatizada foi implantada, serão liquidados os sistemas de prestações definidas e os assalariados serão obrigados a suportar os riscos das Bolsas sobre a poupança que eles terão confiado aos administradores". (CHESNAIS, 2005, p. 62). Dessa feita, a expansão dos fundos de pensão na quadra contemporânea do capitalismo está intimamente relacionada à desestruturação dos regimes previdenciários públicos. (CHESNAIS, 2005; GRANEMANN, 2016; MONTORO, 2016).

A proliferação dos agentes ofertantes de planos da previdência privada, como um todo, e dos fundos de pensão, de modo específico, bem como a ofensiva aos sistemas previdenciários públicos, no centro e na periferia do capital, tem como principais propagadores as agências imperialistas multilaterais, como a OCDE, o Fundo Monetário Internacional (FMI) e o Banco Mundial (BM). A respeito deste último, o emblemático estudo publicado em 1994, denominado Envejecimiento sin Crisis, se constitui em documento orientador da adoção de um esquema de proteção social que seria constituído pelo chamado sistema de três pilares: o primeiro seria um sistema obrigatório básico financiado e administrado pelo setor público; o segundo corresponderia a um sistema obrigatório de administração privada, cujos recursos financiadores seriam provenientes de uma poupança acumulada pelo indivíduo; o terceiro seria um pilar voluntário, direcionado à ampliação do benefício a partir da compra no mercado. Sob tal sistema, o pilar público deveria estar direcionado à garantia de um padrão mínimo comprimido, direcionado a aliviar a pobreza na velhice. (BANCO MUNDIAL, 1994).

Diante de tais postulações do Banco Mundial (1994), é possível conceber que as contrarreformas dos regimes públicos de previdência, a expansão dos programas de transferência de renda mínima e a proliferação dos agentes privados no fornecimento da proteção social são determinações constitutivas da estrutura de proteção social que atende às necessidades da acumulação no capitalismo mundializado.

O delineamento de uma visão panorâmica acerca da presença dos fundos de pensão no centro e na periferia do capital pode ser feito por dois conjuntos de dados: um que forneça a relação proporcional entre os ativos dos fundos de pensão em relação ao Produto Interno Bruto (PIB) de um determinado país, feito pela OECD (2018); e outro que apresente dados acerca dos trezentos maiores fundos de pensão do mundo, elaborado pelo think tank norte-americano Willis Towers Watson (2018).

O estudo da OCDE (2018b), elaborado com dados de 2017, revela que cinco nações capitalistas centrais detêm as maiores proporções de ativos de fundos de pensões em relação a seus respectivos PIBs: Países Baixos (182,5\%); Islândia (151,9\%); Suíça (147,8\%); Austrália (120,9\%); e Reino Unido (105,5\%). No contexto periférico latino-americano, os países que possuem maior proporção de ativos de fundos de pensão em relação a suas rendas nacionais são os seguintes: Chile (72\%); El Salvador (34,5\%); Jamaica (27,8\%); Uruguai (27,3\%); e Colômbia (24,8). O Brasil, por seu turno, possui ativos de fundos de pensão que correspondem a $12 \%$ de seu PIB.

Tais dados ensejam duas inferências: a primeira é que a magnitude dos ativos dos fundos de pensão em relação aos PIBs é um fenômeno mais expressivo em países capitalistas centrais; a segunda é que o percentual do Brasil é relativamente mais baixo do que o de outros países, inclusive latino-americanos. A porcentagem brasileira explicita, por um lado, a existência de um regime público de proteção social relativamente abrangente, que é o Regime Geral de Previdência Social (RGPS), administrado pelo Instituto Nacional do Seguro Social (INSS), e, por outro lado, expõe o fato de que os ativos dos fundos de pensão no país podem se expandir no contexto da contrarreforma das condições de acesso e dos benefícios ofertados pelo sistema público. Granemann (2016) interpreta tal dinâmica da seguinte maneira: "A forma "previdência privada", [...] só poderá resultar importante como mercadoria capaz de acumular massas extraordinárias de riquezas [...] se a Previdência Social for insuficiente e apenas dirigida ao combate à indigência”. (GRANEMANN, 2016, p. 684).

A pesquisa do Instituto Willis Towers Watson (2018) sinaliza algumas tendências relacionacionadas aos trezentos maiores fundos de pensão do mundo, no ano de 2017. A primeira é uma enorme centralização, haja vista que os dois maiores fundos do mundo - Government Pension Investment, do Japão, e o Government Pension Fund, da Noruega - respondem por $9 \%$ do total dos ativos analisados. A segunda tendência vinculase à maciça presença de fundos estatais soberanos e fundos para servidores públicos, que representam $68,6 \%$ do total dos ativos analisados. Uma outra inferência é que os maiores fundos de pensão brasileiros possuem discreta participação entre os trezentos maiores fundos do mundo: o Previ, dos trabalhadores do Banco do Brasil, está na posição 77; o Petros, dos trabalhadores da Petrobrás, tem posição 210; o Funcef, dos trabalhadores da Caixa Econômica Federal, aparece na posição 243.

Como último aspecto a ser abordado na presente seção, é relevante tecer algumas considerações acerca do sistema privado de pensões chileno, o qual tende a ser apresentado pelo Banco Mundial (1994), pelos meios de comunicação hegemônicos e economistas ligados aos mercados financeiros, como bom exemplo de experiência de proteção social. 
O sistema de Administradoras de Fondos de Pensiones (AFP) foi imposto pela Ditadura de Augusto Pinochet ${ }^{4}$, em 1981, e concebido como totalmente privado, não apenas na perspectiva da gestão, mas, também, pelo fato de que somente os trabalhadores contribuem para a configuração dos montantes financeiros. Tratase do regime de capitalização em sua concepção orgânica, pois caracteriza-se pela formação de reservas por parte do trabalhador, as quais, durante o período laboral, devem ser investidas ou aplicadas nos mercados financeiros, com fins de que a massa monetária cresça e possa ser utilizada como fontes de receitas para o pagamento dos benefícios. Sob tal regime, o valor dos benefícios depende do tamanho das reservas, que por sua vez, resultam da combinação das seguintes variáveis: tempo de contribuição; retorno das aplicações; inflação; patamar salarial; e alíquota de contribuição. (ASSOCIAÇÃO NACIONAL DOS AUDITORES FISCAIS DA RECEITA FEDERAL DO BRASIL, 2011).

De acordo com Martínez (2012), o sistema chileno é arriscado para os trabalhadores, individualista e incompatível com um sistema de seguridade social solidário, de modo que "[...] as estatísticas mostram o rosto dramático da pobreza para milhões de cidadãos, que sofrem hoje com suas pensões ou sofrerão assim que se aposentem" (MARTÍNEZ, 2012, p. 48, tradução nossa). O maior problema apontado para o fracasso do sistema chileno é a dificuldade que os trabalhadores têm de acumular fundos que gerem aposentadorias de relevante valor e longa durabilidade. No cenário caracterizado por um mercado de trabalho amplamente informal e salários massivamente rebaixados, os trabalhadores não conseguem formar reservas que garantam benefícios dignos. Apesar da incapacidade de gerar aposentadorias, o sistema é bastante eficiente para alimentar os mercados financeiros, conformando uma lógica que "permite que o capital (ou melhor, uma parte dele) ganhe e os trabalhadores percam". (MONTORO, 2016, p. 395, tradução nossa). A pobreza gerada pelo sistema foi expressa de forma inquientante no título da pesquisa de Martínez (2017), para quem a sigla AFP representa a expressão Aquí se Fabrican Pobres.

Como expressão material do fracasso do sistema chileno em prover aposentadorias dignas, o próprio Estado foi obrigado a criar, em 2008, a Pensão Básica Solidária, que garante um benefício mínimo e rebaixado àqueles que atendem a determinados critérios de renda (MARTÍNEZ, 2017). Ou seja, no Chile, a perversa dinâmica do regime de capitalização imposto aos trabalhadores teve que ser neutralizada a partir da estruturação de um pilar básico de aposentadoria financiado com recursos estatais, conforme sugerido pelo Banco Mundial (1994).

\section{Expansão dos fundos de pensão no Brasil: bases materiais}

No Brasil, a existência de montepios, caixas voluntárias e fundos especiais para militares e funcionários públicos, remetem ao fim do século XIX. Autores como Pinheiro (2007), que concebem os fundos de pensão como mecanismos fornecedores de proteção previdenciária, tendem a interpretar tais instituições como precursoras dos fundos de pensão no país. À luz dessa argumentação, poder-se-ia afirmar que a Caixa Montepio dos Funcionários do Banco da República do Brasil, criada em 1904, teria, linearmente, se convertido no Previ, fundo de pensão com maior massa de ativos financeiros no país.

Porém, essa é uma interpretação vulgar, que ignora o papel de tais fundos como mediações que centralizam recursos provenientes dos salários e alimentam os mercados financeiros. Nessa perspectiva, incorporase a concepção de Granemann (2012), no sentido de que, a interpretação da expansão dos fundos de pensão no Brasil deve conceber as etapas estruturantes que possibilitaram sua materialização como, achados do grande capital, no processo de fazer frente à queda tendencial das taxas de lucro. Portanto, concebe-se que a trajetória de proliferação monetária ${ }^{5}$ dos fundos de pensão no país se constitui em um processo complexo, multideterminado e constituído por três etapas estruturantes, articuladas entre si.

A primeira etapa do estabelecimento das bases materiais refere-se a regulamentações jurídico-formais, que proporcionaram a institucionalização e o primeiro impulso à expansão financeira dos fundos de pensão no país. Isso ocorre durante a Ditadura Militar, com a Lei n ${ }^{\circ} 6.435$, de 15 de julho de 1977 (BRASIL, [2001 a]), que regulamentou a chamada previdência privada. Tal normatização deve ser compreendida em um contexto sócio-político mais amplo, diretamente relacionado à esfera econômica e à configuração da proteção social naquele período.

No âmbito econômico, a produção de condições materiais para atuação de agentes ofertantes de planos de previdência privada se insere nos marcos da estruturação dos mercados financeiros e de capitais durante as décadas de 1960 e 1970, principalmente pela criação do Conselho Monetário Nacional (CMN), em 1964, pelo estabelecimento do marco regulatório do mercado de capitais, pela Lei $\mathrm{n}^{\circ} 4.728$, de 14 de julho de 1965 (BRASIL, [2017]) e pela regulamentação das Sociedades por Ações (S/As), com a Lei $\mathrm{n}^{\circ}$ 6.404, de 15 de dezembro de 1976 (BRASIL, [2019b]).

Além disso, a regulamentação da previdência privada se encontrava no contexto em que Mota (2015) identifica a emergência de uma divisão institucional da seguridade, baseada na segmentação da classe trabalhadora e dos 
benefícios e serviços aos quais cada fração teria acesso: “[...] serviços para os trabalhadores das pequenas e médias empresas nacionais; uma seguridade social própria para o trabalhador da grande empresa [...]; e o INPS [Instituto Nacional de Previdência Social], para os demais trabalhadores". (MOTA, 2015, p. 189, grifo do autor).

A segunda etapa estruturante da expansão dos fundos de pensão no Brasil diz respeito ao processo articulado entre a contrarreforma dos regimes públicos de previdência instituídos no âmbito da CF de 1988 e a reconstituição do marco regulatório da previdência privada.

A contrarreforma dos regimes públicos de previdência, como o RGPS e os regimes próprios dos servidores públicos civis, é um processo contínuo, que, desde meados da década de 1990, tem como objeto a restrição das regras de acesso e a redução da magnitude dos benefícios ofertados ${ }^{6}$. Sua funcionalidade ao capital pode ser atribuída a três movimentos: libera recursos do fundo público para aplicação direta na reprodução do capital, principalmente para pagamento de juros e amortizações da dívida pública; amplia o tempo de trabalho e, com efeito, de subsunção ao capital, de amplos setores da classe trabalhadora; impulsiona a adesão aos planos ofertados pelas instituições da previdência privada. (GRANEMANN, 2016; BOSCHETTI, 2016).

Entre 1995 e 2018, todos os governos que passaram pelo controle do Estado contribuíram à contrarreforma previdenciária: Fernando Henrique Cardoso (FHC), por meio da Emenda Constitucional (EC) ${ }^{\circ} 20$, de 15 de dezembro de 1998 (BRASIL, [2003]) que atingiu principalmente os trabalhadores da iniciativa privada; Luís Inácio Lula da Silva, com a EC no 41, de 19 de dezembro de 2003 (BRASIL, [2016a]), que teve como principal alvo os servidores públicos civis; Dilma Rousseff, por meio da Lei no 13.135 , de 17 de junho de 2015 (BRASIL, [2015a]) e Lei no 13.134, de 16 de junho de 2015 (BRASIL, [2015b]) que restringiram o acesso às pensões por morte e ao seguro-desemprego; Michel Temer, pela tentativa de aprovação da sanguinária Proposta de Emenda a Constituição (PEC) n ${ }^{\circ} 287$, de 2016 (BRASIL, 2016b), e, também, por intermédio do Programa de Revisão de Benefícios por Incapacidade, que objetivou o cancelamento de milhares de benefícios de auxílios-doença e aposentadorias por invalidez.

No que tange à reconstituição do marco regulatório da previdência privada, nessa segunda etapa estruturante, é possível citar três relevantes eixos de instrumentos normativos. O primeiro foi a alteração, pela $\mathrm{EC} \mathrm{n}^{\circ} 20$, de 1998 (BRASIL, [2003]), do art. 202 da Carta de 1988, estabelecendo que o regime de previdência privada, organizado de forma autônoma em relação ao regime geral de previdência social, será facultativo, baseado na constituição de reservas que garantam o benefício contratado. $\mathrm{O}$ segundo eixo de instrumentos corresponde à regulamentação do referido artigo, por meio das Leis Complementares $\mathrm{n}^{\circ} 108$ (BRASIL, [2001b]) e 109 de 29 de maio de 2001 (BRASIL, [2010]), que dispõem, respectivamente, sobre a relação dos entes federados com suas entidades fechadas de previdência complementar, bem como sobre o regime de previdência complementar em sentido amplo. O terceiro eixo diz respei-

Ao capturarem parcelas mensais dos salários, os fundos de pensão agregam volumosos recursos financeiros e se consolidam como agentes dotados de maciço poder monetário. to à criação da Superintendência Nacional de Previdência Complementar (PREVIC), por meio da Lei no 12.154 , de 23 de dezembro de 2009 (BRASIL, [2012]). A criação de tal instituição regulatória, com status jurídico de autarquia, representou a legitimação e o fortalecimento do setor ofertante de planos de previdência privada no Brasil.

A terceira etapa estruturante desdobra-se da etapa anterior e diz respeito a um formidável impulso à criação de fundos de pensão para servidores públicos civis dos entes federados. Conforme afirmado na seção anterior, fundos de pensão para servidores públicos representam amplo percentual dos ativos dos maiores fundos do mundo. Na realidade brasileira, os fundos de pensão para servidores representam o segundo pilar sugerido pelo Banco Mundial (1994) e, na concepção de Salvador (2011), revestem-se de amplo potencial de acúmulo de ativos financeiros, pois, por um lado, tais trabalhadores possuem estabilidade do vínculo empregatício e, por outro, detêm patamar salarial relativamente maior do que os trabalhadores do setor privado.

Nos marcos da contrarreforma dos regimes próprios dos servidores públicos, diversas mudanças normativas foram feitas com vistas a impulsionar a criação de fundos de pensões a tal segmento. Ato relevante foi a $\mathrm{EC} \mathrm{n}^{\circ}$ 20, de 1998 (BRASIL, [2003]), que inseriu no art. 40 do texto constitucional, o § 14, que versa que a instituição de entidades fechadas de previdência complementar pelos entes federados exige a imposição do teto do RGPS como valor máximo das aposentadorias dos regimes próprios. Em 1999, o governo FHC, por meio do Projeto de Lei Complementar $n^{\circ} 9$ (BRASIL, 1999), tentou implantar normas gerais para o funcionamento da previdência complementar no âmbito de todos os entes federados, mas o projeto não foi convertido em lei.

A expansão dos fundos de pensão para servidores públicos alcançou patamar mais qualificado durante os governos do Partido dos Trabalhadores (PT). No governo Lula, a EC n ${ }^{\circ}$ 41, de 2003 (BRASIL, [2016a]), 
além de restringir o acesso aos benefícios ofertados pelos regimes próprios e impor contribuição aos servidores inativos, estabeleceu a modalidade de benefício de contribuição definida no âmbito dos fundos de pensão para servidores, a qual torna o valor do benefício vulnerável aos rendimentos das aplicações financeiras. O sucesso de tal governo em ampliar o ramo de atuação da previdência privada foi assim interpretado por Lesbaupin (2003, p. 14): "O governo Lula conseguiu aprovar na Câmara Federal e no Senado, em poucos meses, o que o governo anterior tentara durante anos e não obtivera: a taxação dos servidores inativos. E conseguiu abrir para o setor privado uma parte importante da Previdência".

Em 2012, o governo Dilma Rousseff aprofundou o processo de impulso à criação de fundos de pensão para servidores públicos a partir da Lei n ${ }^{\circ} 12.618$, de 30 de abril de 2012 (BRASIL, 2016b), que regulamentou e autorizou a criação, pela União, de três fundos de pensão, os quais receberam a denominação de Fundação de Previdência Complementar do Servidor Público Federal (FUNPRESP): FUNPRESP-EXE, para os servidores do Poder Executivo; FUNPRESP-LEG para o Poder Legislativo; FUNPRESP-JUD, para servidores do Judiciário. Em consonância com tal legislação federal, a partir do ano de 2011, houve considerável expansão da implantação de fundos para servidores públicos por parte de diversos entes federados.

No ano de 2015, por meio da Lei $\mathrm{n}^{\circ} 13.183$, de 4 de novembro (BRASIL, [2015c]), promoveu-se uma arbitrária alteração na Lei n ${ }^{\circ}$ 12.618, de 2012 (BRASIL, [2016b]), no sentido de estabelecer que a adesão à Funpresp deixaria de ser pela opção do próprio servidor e passaria a ser automática. Complementando tal conjuntura, o governo de Michel Temer apresentou à Câmara dos Deputados o Projeto de Lei (PL) n ${ }^{\circ} 6.088$, de 2016 (BRASIL, 2016a), por meio do qual intenta-se permitir que os planos de benefícios criados nas esferas estaduais, distritais e municipais sejam administrados pela FUNPRESP-EXE. Tal proposição, se aprovada, expandirá, significativamente, o já maciço poder monetário de tal fundo.

A Tabela 1 apresenta dados referentes aos maiores fundos de pensão para servidores públicos criados pelos entes federativos entre os anos de 2008 e 2016, incluindo-se os valores de seus ativos financeiros e a posição de cada um no ranking elaborado pela $\mathrm{ABRAPP}^{7}$, que ordena 252 fundos a partir dos ativos financeiros. Além da União, observa-se a criação de fundos de pensão por todos os estados da região sudeste, dois da região sul - Santa Catarina e Rio Grande do Sul -, e duas unidades da federação da região nordeste - Pernambuco e Bahia.

Os dados constantes na Tabela 1 evidenciam o amplo potencial de acúmulo de massas monetárias dos fundos criados para servidores federais, particularmente o Funpresp-Exe, que, em julho de 2018, superava o montante de R\$ 1 bilhão em ativos financeiros e ocupava a posição centésima, no ranking da ABRAPP. Observa-se que o fundo dos servidores do estado de São Paulo é o segundo maior dentre os fundos selecionados, cujo montante de ativos, de R \$ 974 bilhões, se aproxima do valor de um bilhão de reais. Também é possível observar que, em conjunto, os fundos criados para servidores públicos acumularam mais de $\mathrm{R} \$ 2,3$ bilhões em ativos, os quais, se fossem centralizados em um único fundo, ocupariam a posição 59 no ranking da ABRAPP de julho de 2018.

Tabela 1 - Maiores fundos de pensão para servidores públicos criados por entes federativos brasileiros (2008 - 2016)

\begin{tabular}{lcccc}
\hline Ente federativo & Nome & Criação & Ativos (em R\$ milhões) & Ranking ABRAPP \\
\hline Pernambuco & ALEPEPREV & 2008 & 39 & 237 \\
São Paulo & SP-PREVCOM & 2011 & 974 & 103 \\
União & Funpresp-Exe (1) & 2012 & 1.006 & 100 \\
União & Funpresp-Jud & 2012 & 236 & 196 \\
Rio de Janeiro & RJPREV & 2012 & 55 & 233 \\
Minas Gerais & PREVCOM-MG & 2014 & 5 & 247 \\
Espírito Santo & PREVES & 2014 & 44 & 236 \\
Bahia & PREVBAHIA & 2015 & 4 & 248 \\
Santa Catarina & SCPREV & 2015 & 3 & 249 \\
Rio Grande do Sul & RS-PREV & 2016 & 12 & 243 \\
\hline Total & - & - & 2.378 & 59 \\
\hline
\end{tabular}

Fonte: Consolidado Estatístico daABRAPP, de julho de 2018. Elaboração própria.

Notas: Valores em R\$ de julho de 2018.

(1) Oplano de benefícios dos servidores do Poder Legislativo Federal é ofertado pela FUNPRESP-EXE. 
Em última instância, observa-se que os fundos de pensão criados para servidores públicos acumulam massas monetárias extraordinárias, o que explicita o real interesse que, desde a década de 1990, permeou a imposição de regras restritivas de acesso aos regimes próprios e o impulso à regulamentação do regime privado para servidores: a necessidade de alimentar os mercados financeiros. Ao capturarem parcelas mensais dos salários, os fundos de pensão agregam volumosos recursos financeiros e se consolidam como agentes dotados de maciço poder monetário. Tal dinâmica foi magistralmente descrita por Marx (1986, p. 303): "Pequenas somas, cada uma por si incapaz de atuar como capital monetário, são unificadas em grandes massas e constituem assim um poder monetário".

\section{Considerações finais}

No centro e na periferia do capitalismo, a ofensiva aos regimes públicos de previdência social é uma expressão do ataque capitalista contra a classe trabalhadora e um dos principais objetivos desse processo é a busca pela expansão dos mecanismos ofertantes da previdência privada. A partir do arcabouço teóricometodológico marxista, este artigo teve como objetivo propor elementos críticos à dinâmica de funcionamento dos fundos de pensão no Brasil.

Uma visão panorâmica dos fundos de pensão no contexto de mundialização, crise e ofensiva neoliberal, indica que tais fundos se mostram funcionais à acumulação capitalista, a partir de seu potencial de alimentação dos mercados financeiros. A configuração dos fundos de pensão no mundo revela que os países capitalistas centrais detêm maior parcela dos ativos de tais fundos. No Brasil, o patamar relativamente baixo dos ativos revela um potencial de crescimento que, para ser alcançado, pressupõe a contrarreforma das condições de acesso e rebaixamento dos valores dos benefícios ofertados pelos regimes públicos instituídos pela Carta Magna de 1988.

$\mathrm{O}$ uso dos fundos de pensão destinados a servidores públicos como instrumento para sua expansão monetária no Brasil enseja uma contradição, pois um dos argumentos utilizados para a contrarreforma dos regimes próprios diz respeito à existência de um déficit e a consequente necessidade de acionamentos aos orçamentos dos entes federados para cobrí-los. $\mathrm{O}$ fato de que recursos estatais e salários dos servidores são usados para expandir os ativos dos fundos de pensão sugere que os interesses em torno da contrarreforma e da expansão da previdência privada não estão relacionados à necessidade de sanear as contas públicas, mas à ampla capacidade que os fundos de pensão possuem para alimentar os mercados financeiros.

Verifica-se, portanto, validade à hipótese proposta, pois os fundos de pensão não estão direcionados à garantia da proteção previdenciária, mas à submissão de amplas massas monetárias à acumulação capitalista.

\section{Referências}

ASSOCIAÇÃO BRASILEIRADAS ENTIDADES FECHADAS DE PREVIDÊNCIACOMPLEMENTAR. Consolidado estatístico. [S. 1.], 2018. Disponível em: http://www.abrapp.org.br/Consolidados/Consolidado\%20Estat\%C3\%ADstico_07.2018.pdf. Acesso em: 14 dez. 2018. ASSOCIAÇÃO NACIONAL DOS AUDITORES FISCAIS DA RECEITA FEDERAL DO BRASIL. Previdência complementar do servidor público: críticas e questionamentos ao projeto de Lei nº 1.992/2007. Brasília, DF, 2011. Disponível em: https://www.anfip.org.br/ livros/. Acesso em: 2 out. 2019.

BANCO MUNDIAL. Envejecimiento sin crisis: política para la protección de los ancianos y la promoción del crecimiento. Washington, D.C., 1994.

BOSCHETTI. I. Assistência social e trabalho no capitalismo. São Paulo: Cortez, 2016.

BRASIL. [Constituição (1988)]. Constituição Da República Federativa do Brasil de 1988. Brasília, DF: Presidência da República, [2019a]. Disponível em: http://www.planalto.gov.br/ccivil_03/constituicao/ConstituicaoCompilado.htm. Acesso em: 9 ago. 2019.

BRASIL. [Constituição (1988)]. Emenda constitucional $n^{\circ}$ 20, de 15 de dezembro de 1998. Modifica o sistema de previdência social, estabelece normas de transição e dá outras providências. Brasília, DF: Presidência da República, [2003]. Disponível em: http:// www.planalto.gov.br/ccivil_03/constituicao/emendas/emc/emc20.htm. Acesso em: 9 ago. 2019.

BRASIL.[Constituição (1988)]. Emenda constitucional n ${ }^{\circ} 41$ de 19 de dezembro de 2003. Modifica os arts. 37, 40, 42, 48, 96,149 e 201 da Constituição Federal, revoga o inciso IX do $\S 3$ do art. 142 da Constituição Federal e dispositivos da Emenda Constitucional n 20 , de 15 de dezembro de 1998, e dá outras providências. Brasília, DF: Congresso Nacional, [2016a]. Disponível em: http://www.previdencia.gov.br/ perguntas-frequentes/emenda-constitucional-no-41-de-19-de-dezembro-de-2003-dou-de-31122003/. Acesso em: 9 ago. 2019.

BRASIL. Câmara dos Deputados. Projeto de lei PLP 9/1999. Dispõe sobre as normas gerais para a instituição de regime de previdência complementar pela União, pelos Estados, pelo Distrito Federal e pelos Municípios. Brasília, DF, 16 mar. 1999. Disponível em: https:// www.camara.leg.br/proposicoesWeb/fichadetramitacao?idProposicao=21321. Acesso em: 9 ago. 2019. 
BRASIL. Câmara dos Deputados. Projeto de lei PL 6088/2016. Altera a Lei no 12.618 , de 30 de abril de 2012, para permitir que planos de benefícios estaduais, distritais e municipais possam ser administrados pela Funpresp-Exe, e a Lei $n^{\circ} 9.717$, de 27 de novembro de 1998, para tratar sobre a emissão de Certificado de Regularidade Previdenciária - CRP. Brasília, DF, 6 set. 2016a. Disponível em: https:/ /www.camara.leg.br/proposicoesWeb/fichadetramitacao?idProposicao=2110989. Acesso em: 9 ago. 2019.

BRASIL. Câmara dos Deputados. Proposta de Emenda à Constituição PEC 287/2016. Altera os arts. 37, 40, 109, 149, 167, 195, 201 e 203 da Constituição, para dispor sobre a seguridade social, estabelece regras de transição e dá outras providências. Brasília, DF, 5 dez. 2016b. Disponível em: https://www.camara.leg.br/proposicoesWeb/fichadetramitacao?idProposicao=2119881. Acesso em: 9 ago. 2019.

BRASIL. Lei Complementar $n^{\circ}$ 108, de 29 de maio de 2001. Dispõe sobre a relação entre a União, os Estados, o Distrito Federal e os Municípios, suas autarquias, fundações, sociedades de economia mista e outras entidades públicas e suas respectivas entidades fechadas de previdência complementar, e dá outras providências. Brasília, DF: Presidência da República, [2001b]. Disponível em: http:// www.planalto.gov.br/ccivil_03/leis/lcp/Lcp108.htm. Acesso em: 9 ago. 2019.

BRASIL. Lei Complementar $n^{\circ}$ 109, de 29 de maio de 2001. Dispõe sobre o Regime de Previdência Complementar e dá outras providências. Brasília, DF: Presidência da República, [2010]. Disponível em: http://www.planalto.gov.br/ccivil_03/LEIS/LCP/ Lcp109.htm. Acesso em: 9 ago. 2019.

BRASIL. Lei $n^{\circ}$ 4.728, de 14 de julho de 1965. Disciplina o mercado de capitais e estabelece medidas para o seu desenvolvimento. Brasília, DF: Presidência da República, [2017]. Disponível em: http://www.planalto.gov.br/ccivil_03/LEIS/L4728.htm. Acesso em: 9 ago. 2019.

BRASIL. Lei $n^{\circ}$ 6.404, de 15 de dezembro de 1976. Dispõe sobre as Sociedades por Ações. Brasília, DF: Presidência da República, [2019b]. Disponível em: http://www.planalto.gov.br/ccivil_03/leis/16404consol.htm. Acesso em: 9 ago. 2019.

BRASIL. Lei $n^{\circ}$ 6.435, de 15 de julho de 1977. Dispõe sobre as entidades de previdência privada. Brasília, DF: Presidência da República, [2001a]. Disponível em: http://www.planalto.gov.br/ccivil_03/LEIS/L6435impressao.htm. Acesso em: 9 ago. 2019.

BRASIL. Lei $n^{\circ}$ 12.154, de 23 de dezembro de 2009. Cria a Superintendência Nacional de Previdência Complementar - PREVIC e dispõe sobre o seu pessoal; inclui a Câmara de Recursos da Previdência Complementar na estrutura básica do Ministério da Previdência Social; altera disposições referentes a auditores-fiscais da Receita Federal do Brasil; altera as Leis $\mathrm{n}^{\circ \mathrm{s}} 11.457$, de 16 de março de 2007, e 10.683, de 28 de maio de 2003; e dá outras providências. Brasília, DF: Presidência da República, [2012]. Disponível em: http://www.planalto.gov.br/ ccivil_03/_Ato2007-2010/2009/Lei/L12154.htm. Acesso em: 9 ago. 2019.

BRASIL. Lei $n^{\circ} 12.618$, de 30 de abril de 2012. Institui o regime de previdência complementar para os servidores públicos federais titulares de cargo efetivo, inclusive os membros dos órgãos que menciona; fixa o limite máximo para a concessão de aposentadorias e pensões pelo regime de previdência de que trata o art. 40 da Constituição Federal; autoriza a criação de 3 (três) entidades fechadas de previdência complementar, denominadas Fundação de Previdência Complementar do Servidor Público Federal do Poder Executivo (Funpresp-Exe), Fundação de Previdência Complementar do Servidor Público Federal do Poder Legislativo (Funpresp-Leg) e Fundação de Previdência Complementar do Servidor Público Federal do Poder Judiciário (Funpresp-Jud); altera dispositivos da Lei n 10.887 , de 18 de junho de 2004; e dá outras providências. Brasília, DF: Presidência da República, [2016b]. Disponível em: http://www.planalto.gov.br/ ccivil_03/_Ato2011-2014/2012/Lei/L12618.htm. Acesso em: 9 ago. 2019.

BRASIL. Lei $n^{\circ} 13.134$, de 16 de junho de 2015. Altera as Leis $n^{\circ} 7.998$, de 11 de janeiro de 1990, que regula o Programa do SeguroDesemprego e o Abono Salarial e institui o Fundo de Amparo ao Trabalhador (FAT), n ${ }^{\circ} 10.779$, de 25 de novembro de 2003, que dispõe sobre o seguro-desemprego para o pescador artesanal, e $\mathrm{n}^{\circ} 8.213$, de 24 de julho de 1991, que dispõe sobre os planos de benefícios da Previdência Social; revoga dispositivos da Lei ${ }^{\circ} 7.998$, de 11 de janeiro de 1990, e as Leis $n^{\circ} 7.859$, de 25 de outubro de 1989, e nº 8.900, de 30 de junho de 1994; e dá outras providências. Brasília, DF: Presidência da República, [2015b]. Disponível em: http:// www.planalto.gov.br/ccivil_03/_Ato2015-2018/2015/Lei/L13134.htm. Acesso em: 9 ago. 2019.

BRASIL. Lei $n^{\circ} 13.135$, de 17 de junho de 2015. Altera as Leis $n^{\circ} 8.213$, de 24 de julho de 1991, $n^{\circ} 10.876$, de 2 de junho de 2004, $n^{\circ}$ 8.112, de 11 de dezembro de 1990, e n 10.666, de 8 de maio de 2003, e dá outras providências. Brasília, DF: Presidência da República, [2015a]. Disponível em: Acesso em: 9 ago. 2019.

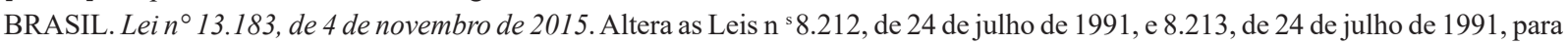
tratar da associação do segurado especial em cooperativa de crédito rural e, ainda essa última, para atualizar o rol de dependentes, estabelecer regra de não incidência do fator previdenciário, regras de pensão por morte e de empréstimo consignado, a Lei n ${ }^{\circ} 10.779$, de 25 de novembro de 2003, para assegurar pagamento do seguro-defeso para familiar que exerça atividade de apoio à pesca, a Lei n $\mathrm{n}^{\circ} 12.618$, de 30 de abril de 2012, para estabelecer regra de inscrição no regime de previdência complementar dos servidores públicos federais titulares de cargo efetivo, a Lei $\mathrm{n}^{\circ} 10.820$, de 17 de dezembro de 2003, para dispor sobre o pagamento de empréstimos realizados por participantes e assistidos com entidades fechadas e abertas de previdência complementar e a Lei nº 7.998, de 11 de janeiro de 1990; e dá outras providências. Brasília, DF: Presidência da República, [2015c]. Disponível em: http://www.planalto.gov.br/ccivil_03/_Ato20152018/2015/Lei/L13183.htm. Acesso em: 9 ago. 2019.

CARAMURU, T. S. Contrarreforma da Previdência Social sob a égide do capital portador de juros: uma ofensiva a serviço da “previdência privada”. 2017. Dissertação (Mestrado em Política Social) - Universidade de Brasília, Brasília, DF, 2017.

CHESNAIS, F. O capital portador de juros: acumulação, internacionalização, efeitos econômicos e políticos. In: CHESNAIS, F. (org.). A finança mundializada: raízes sociais e políticas, configuração, conseqüências. São Paulo: Boitempo, 2005. p. 35-67. 
GRANEMANN, S. Fundos de pensão e a metamorfose do "salário em capital”. In: SALVADOR, E; BEHRING, E; BOSCHETTI, I.; GRANEMANN, S. (org.). Financeirização, fundo público e política social. São Paulo: Cortez, 2012. p. 243-260.

GRANEMANN, S. PEC 287/16: falácias para a desconstrução dos direitos do trabalho. SER Social, Brasília, v. 18, n. 39, p. 672-688, jul./dez. 2016.

HENRIQUE, A. C. A gestão de capital nos fundos de pensão: uma abordagem sob o crivo da análise jurídica da política econômica AJPE. 2018. Dissertação (Mestrado em Direito) - Faculdade de Direito, Universidade de Brasília, 2018.

LESBAUPIN, I. Governo Lula: um balanço do primeiro ano. Praia Vermelha, Rio de Janeiro, v. 1, n. 9, p. 10-33, 2003.

MARTÍNEZ, C. R. Aquí se frabrican pobres: el sistema privado de pensiones chileno. Santiago de Chile: LOM Ediciones, 2017.

MARTÍNEZ, C. R. El sistema privado de pensiones chileno: injusto, riesgoso e insuficiente. Derecho y justicia. Santiago de Chile, n. 2 , p. 47-67, 2012.

MARX, K. O capital: crítica da economia política: o processo global da produção capitalista. 2. ed. São Paulo: Nova Cultural, 1986. v. 3 , t. 2. MONTORO, X. A. Capitalismo y economía mundial: bases teóricas y análisis empírico para la comprencíon de los problemas económicos del siglo XXI. 2. ed. [Madrid]: Instituto Marxista de Economía, 2016.

MOTA, A. E. Cultura da crise e seguridade social. 7. ed. São Paulo: Cortez, 2015.

ORGANIZATION FOR ECONOMIC CO-OPERATION AND DEVELOPMENT. Pension Markets in Focus: 2018. [S. l.]: ORGANIZATION FOR ECONOMIC CO-OPERATION AND DEVELOPMENT, 2018a. Disponível em: http://www.oecd.org/daf/ fin/private-pensions/Pension-Markets-in-Focus-2018.pdf. Acesso em 18 dez. 2018.

ORGANIZATION FOR ECONOMIC CO-OPERATION AND DEVELOPMENT. Pension funds in figures. [S. l.]: ORGANIZATION FOR ECONOMIC CO-OPERATION AND DEVELOPMENT, 2018b. Disponível em: http://www.oecd.org/daf/fin/private-pensions/ Pension-Funds-in-Figures-2018.pdf. Acesso em: 2 dez. 2018.

PINHEIRO, R. P. A demografia dos fundos de pensão. Brasília, DF: Ministério da Previdência Social, 2007. 24 v.

SALVADOR, E. A Privatização da Previdência do Servidor Público: a FUNPRESP e a financeirização das aposentadorias e pensões. Cadernos ASLEGIS, Brasília, DF, n. 43, p. 107-123, maio/ago. 2011. Disponível em: http:/www.aslegis.org.br/files/cadernos/2011/ Caderno43/CAD.43p107_A.privatizacao.da.previdencia.do.servidor.publico.a.fuvnpresp.e.a.financeirizacao.das.aposentadorias.e. pensoes.pdf. Acesso em: 9 ago. 2019.

WILLIS TOWERS WATSON. Pensions \& Investments: Thinking Ahead Institute world 300: year end 2017. [London]: WILLIS TOWERS WATSON, 2018. 46 slides.

\section{Notas}

1 As entidades abertas de previdência complementar são organizações constituídas como sociedades anônimas, estruturadas por bancos e/ou seguradoras, que vendem planos de previdência no mercado ao público em geral.

2 Outra espécie de fundos de pensão são aqueles denominados instituídos, que podem ser criados por sindicatos e associações profissionais.

3 Além dos fundos de pensão, são investidores institucionais: as companhias de seguro, sociedades financeiras de investimento coletivo (Mutual Funds), fundos de investimentos, hedge funds, dentre outros.

4 Montoro (2016) assinala o interessante fato de que, para os militares chilenos, continuam vigentes as caixas regidas por repartição simples, com participação do Estado e sem os riscos ensejados pela capitalização.

5 Estudo de Caramuru (2017) aponta que a proliferação dos fundos de pensão no Brasil se consolida na dimensão dos ativos financeiros, e não na quantidade de fundos ou de trabalhadores a eles vinculados.

6 Outra dimensão da contrarreforma previdenciária corresponde à corrosão das receitas, por meio de mecanismos como a Desregulamentação das Receitas da União(DRU); políticas de isenções e desonerações das contribuições previdenciárias; e a existência de institucionalidade favorável à sonegação. (CARAMURU, 2017).

7 Enfatiza-se que a análise se restringiu aos fundos de pensão que estão no consolidado emitido pela ABRAPP em julho de 2018, constante em ABRAPP (2018).

Thais Soares Caramuru

tcaramuru@gmail.com

Mestre em Política Social pela Universidade de Brasília (UnB)

\section{UnB}

Departamento de Serviço Social

Campus Universitário Darcy Ribeiro - ICC Norte - Asa Norte

Brasília - DF - Brasil

CEP: 70910-900 


\section{Agradecimentos}

Ao Programa de Pós-Graduação em Política Social da Universidade de Brasília.

Agência financiadora

Não se aplica.

Contribuições dos autores

Não se aplica.
Aprovação por Comitê de Ética e consentimento para participação

Não se aplica.

Consentimento para publicação

Não se aplica.

Conflito de interesses

Não há conflito de interesses. 